\section{EMBRYRIDDLE \\ Aeronautical University}

SCHOLARLY COMMONS
International Journal of Aviation, Aeronautics, and Aerospace

\title{
Characteristics of Helicopter Accidents Involving Male and Female Pilots
}

\author{
Scott S. Burgess \\ Embry-Riddle Aeronautical University - Worldwide, burgesco@erau.edu \\ Robert O. Walton \\ Embry-Riddle Aeronautical University - Worldwide, waltonr@erau.edu \\ P. Michael Politano \\ The Citadel, politanom@citadel.edu
}

Follow this and additional works at: https://commons.erau.edu/ijaaa

Part of the Aviation Safety and Security Commons, Other Kinesiology Commons, Other Physiology Commons, and the Risk Analysis Commons

\section{Scholarly Commons Citation}

Burgess, S. S., Walton, R. O., \& Politano, P. (2018). Characteristics of Helicopter Accidents Involving Male and Female Pilots. International Journal of Aviation, Aeronautics, and Aerospace, 5(2). https://doi.org/ 10.15394/ijaaa.2018.1216

This Article is brought to you for free and open access by the Journals at Scholarly Commons. It has been accepted for inclusion in International Journal of Aviation, Aeronautics, and Aerospace by an authorized administrator of Scholarly Commons. For more information, please contact commons@erau.edu. 
The predominantly fixed-wing General Aviation (GA, 14 U.S. Code of Federal Regulation (CFR) Part 91) industry is defined as "the operation of civilian aircraft for purposes other than commercial, passenger, [or cargo] transport, including personal, business, and instructional flying" (Bazargan \& Guzhva, 2011, p. 962). This segment accounts for $94 \%$ of all air related accidents in the United States with a fatality rate of 1.31 per 100,000 flight hours (Li \& Baker, 2007; Shao, Guindani, \& Boyd, 2014; USHJSAT, 2011). Studies examining fixed-wing aviation accidents have not found differences in accident rates by gender though there may be gender differences by type of accident (Bazargan \& Guzhva, 2011; Caldwell \& LeDuc, 1998; McFadden, 1996; Mitchell et al., 2005; Puckett \& Hynes, 2011; Vail \& Ekman, 1986; Walton \& Politano, 2016). In one recent study, Bazargan and Guzhva (2011) examined the impact of gender, age and experience of GA pilots involved in fixed-wing accidents. Using the National Transportation Safety Board (NTSB) aviation accident database system (eADMS), Bazargan and Guzhva found pilots with lower flight times were more likely to make errors leading to accidents; however, lower flight hour accidents were not related to gender. Bazargan and Guzhva also found fatalities increased with pilot experience. Previous studies (e.g., Mitchell et al., 2005; Puckett \& Hynes, 2011) have not supported, generally, any real differences in abilities between male and female pilots in the fixed-wing segment of the aviation industry.

In this study, the objective was to determine if gender patterns found in fixed wing also appear in rotary-wing aircraft (helicopters) by using the injury and damage data from the NTSB eADMS database. While women constitute six percent of the fixed-wing aviation pilot population (Mitchell, Kristovics, \& Bishop, 2010), far fewer hold helicopter certifications. The NTSB database (1982 to 2014) contains 74,686 records of accidents, of which 6,678 are helicopter accidents. Of all air-related accidents in the United States, 94\% have been fixed-wing at a rate of 1.31 per 100,000 flight hours (USHJSAT, 2011). By comparison, helicopter accidents occur at a rate of 9.1 accidents per 100,000 flight hours (USJHIMDAT, 2014). Seventy percent of helicopter accidents occur with pilots having less than 1500 hours of flight time (USJHIMDAT, 2014).

With this background in mind, this study was an examination of gender differences for accidents in helicopters. As such, it extends the findings of Baker, Lamb, Grabowski, Rebok, and Li (2001), Bazargan and Guzhva (2011), and Walton and Politano (2016), to helicopter pilots.

Fixed-wing GA aircraft accident rates for males appear similar to motor vehicle accident rates, reflecting higher male fatalities (Baker, Lamb, Grabowski, Rebok, \& Li, 2001). Parallel to gender characteristics of male auto accidents, Baker 
et al., (2001) found male pilots may be more likely to take risks and have accidents related to inattention or poor planning (e.g., ignoring weather conditions, taking unnecessary risks). Female pilots, by comparison, were found to be more likely to have accidents due to mishandling of the aircraft (e.g., panic maneuvers, maintaining aircraft control).

While these findings relate to fixed-wing aircraft, there have not been similar studies of gender differences in the civil helicopter industry. A study by the U.S. Joint Helicopter Safety Analysis Team (USJHSAT, 2011) found that, like fixed-wing aircraft, helicopter accidents were higher during training and in the GA segment of helicopter use as opposed to commercial or industrial (e.g., medivac, news gathering, forestry services and/or external load).

\section{Comparison of fixed-wing verses rotor-wing aircraft}

Fixed-wing aircraft and helicopters differ in essentially four ways: operational axes, inherent stability, number of control input options, and hovering. While both fixed-wing and helicopters operate in forward and lateral dimensions, only helicopters can assume vertical flight (with a few fixed-wing exceptions such as the V-22 Osprey and Harrier), or fly backward. The increased dimensionality of helicopters results in a greater degree of in-flight instability that must be monitored at all times (FAA, 2012; Burgess, 2016). Flight control mechanisms differ between airplane and helicopter in that those in a helicopter are much more complex (Burgess, 2016). Additionally, helicopter hovering is a flight task presenting its unique challenges relative to aircraft control and dimensional awareness by the pilot, e.g., sensing objects in proximity to the aircraft and the wind direction simultaneously.

Given these differences, helicopter pilots are engaged in multitasking to a greater extent than fixed-wing pilots to maintain control of the aircraft and must maintain more omnidirectional situational awareness as compared to fixed-wing pilots (Burgess, 2016). Particularly the spatial awareness would seem to favor males over females where evolutionary processes supposedly favored males in terms of stronger parietal (spatial) functioning (Jones, Braithwaite, \& Healy, 2003). Additionally, the omnidirectional movement of the helicopter generates increased physiological requirements for situational awareness over that of an airplane. This awareness is accentuated as helicopters tend to operate in close proximity to natural and manmade obstacles. Added to this are the low, medium and high-frequency vibrations from engines, multiple gearboxes and transmissions, and rotors (FAA, 2012). In short, the sensory load, multiple spatial dimensions, as well as the ability, and sometimes necessity, to operate in close proximity to objects requires skills that are not necessary in fixed-wing flight. 
Aeronautical decision-making does appear quite frequently in helicopter accident literature as a leading causal factor in accidents (Bryan, 2014; Nix, Buckner, \& Cercone, 2014; Szymczak, 2008). Other contributing factors to accidents include loss of control with hovering and low-speed helicopter flight as confounding factors (NASA, 2006).

\section{Method}

\section{Procedure}

This research utilized the NTSB aviation accident and incident database system (eADMS) from 1982 to 2014 to examine differences in the severity of accidents by gender for helicopter pilots. The NTSB dataset uses very strict published coding instructions for each accident (damage to plane or injury to individuals) and incident (all other events) using a Brief-of-Accident or Brief-ofIncident format. Each brief includes NTSB findings, which are coded by sequence of events such as occurrences, phases of flight, weather conditions, sky conditions, age and gender of pilot, etc. Of particular interest in these data for this study were number of flight hours for the pilots, degree of damage to the helicopter (None, Minimal, Substantial, Destroyed), and degree of bodily injury (None, Minor, Serious, Fatal) (NTSB, 1998). All data in the database were substantiated, as documented in the Factual Report or as available in other accessible documents or publications (NTSB, 1998). There were 74,686 accident/incident entries in the database. For this study, only the 6,678 helicopter accidents/incidents were included.

\section{Participants}

There were 6,552 (98.11\%) male pilots and 126 (1.89\%) female helicopter pilots involved in accidents. The mean age for all helicopter pilots was 42.12 (SD $=11.66)$. The average age for male pilots was $42.13(S D=11.35)$ and for female pilots, $35.98(S D=10.64)$. There was a statistically significant age difference, $t(6814)=6.09, p<.001$.

The total number of flight hours was used as an indicator of pilot experience and divided into five categories based on FAR Part 61 guidance and consistent with Bazargan and Guzhva (2011) and Walton and Politano (2016). The five pilot experience categories were: Category I (New Pilots) for pilots who had 99 or fewer hours of total flight time, Category II (Moderate Experience) for pilots with 100 to 299 hours of flight time, Category III (Fairly Experienced) for pilots with flight times between 300 and 1999 hours, Category IV (Very Experienced) for pilots with 
flight times between 2000 and 4999, and Category V (Most Experienced) for pilots with more than 5000 hours. Average flight hours for all helicopter pilots was 5263.09 ( $S D=5895.86)$. A Mann-Whitney test indicated that flight hours were significantly greater for males $(M d n=3267)$ than for females $(M d n=794), U=$ $-6.59, p<.001$. The mean flight hours for male pilots was $5292.36(S D=5853.57)$, and for female pilots the mean was $2741.36(S D=4230.57)$. This was a significant difference $(p<.001)$. In the examination of flight hour categories following FAR Part 61 guidance, Bazargan and Guzhva (2011), and Walton and Politano (2016), female pilots were significantly over-represented in the lowest flight hour categories (CAT I and II), and significantly underrepresented in the highest flight hour category (CAT V), see table 1 .

Male pilots were more represented in air medical operations, $4.29 \%$ compared to $1.58 \%$ for female pilots. Male pilots were more heavily represented in FAR Part 91 (GA), 97.8\% compared to female pilots at 2.2\%. Finally, male pilots were more heavily represented in commercial operations (FAR Parts 133, 135, 137) at $99.02 \%$, with $0.98 \%$ for female pilots. Differences between male and female helicopter pilots across FAR Part 61, experience level by flight hours, and damage and injury categories were analyzed using the Test for Significance of a Difference Between Two Independent Proportions. Proportional comparisons were used to compensate for the disparity in the number of male versus female pilots.

\section{Results}

There were significant differences between male and female pilots at FAR Part 61 Categories of I and II (CAT I and II) with females significantly overrepresented at the lower experience categories (see Table 1). Female pilots were also significantly underrepresented at the highest number of flight hours (CAT $\mathrm{V}$, Table 1). There were no significant differences proportionally at CAT III or IV.

Table 1

Experience Categories (CAT I, II, III, IV, V) between Male and Female Pilots

\begin{tabular}{lcccc}
\hline Category--hours & $\begin{array}{c}\text { Male } \\
\text { percent }\end{array}$ & $\begin{array}{c}\text { Female } \\
\text { percent }\end{array}$ & $z$-score & $p$ \\
\hline CAT I 00-99 & 5.37 & 14.06 & -4.26 & $<.0001$ \\
CAT II 100-299 & 7.58 & 16.41 & -3.70 & $<.0002$ \\
CAT III 300-1999 & 25.32 & 32.03 & -1.73 & .0842 \\
CAT IV 2000-4999 & 22.54 & 17.97 & 1.23 & .22 \\
CAT V 4999 plus & 39.19 & 19.53 & 4.52 & $<.0002$ \\
\hline
\end{tabular}

*Significance of the difference in proportion, $z>1.96, p<.05$ 
When damage and injuries were examined for male and female helicopter pilots irrespective of experience, no significant differences were found for damage to the aircraft (see Table 2). While not a significant difference, female pilots were higher than male pilots in Substantial damage (82.03\% to $76.86 \%$, respectively) and lower than male pilots in Destroyed (16.41\% to $20.02 \%$, respectively) (see Table 2).

Table 2

Damage Levels for Male and Female Pilots

\begin{tabular}{lcccc}
\hline Damage & Male percent & Female percent & $z$-score & $p$ \\
\hline None & 1.45 & 0.0 & -- & -- \\
Minor & 1.67 & 1.56 & .092 & .9267 \\
Substantial & 76.86 & 82.03 & -1.376 & .1688 \\
Destroyed aircraft & 20.02 & 16.41 & 1.014 & .3106 \\
\hline
\end{tabular}

There were also no significant differences in injuries between male and female pilots (see Table 3). While not significant, female pilots were lower in fatalities (10.16\% to $15.24 \%$, respectively), lower, but not significantly so, in minor injuries (18.75\% to $19.23 \%$, respectively) and higher, but not significantly so, in serious injuries (12.50\% to $11.61 \%$, respectively). Overall, male and female pilots had nearly the same track records regarding aircraft damage or injuries following an accident.

Table 3

Injury levels for Male and Female Pilots

\begin{tabular}{lcccc}
\hline Highest Injury & Male percent & Female percent & $z$-score & $p$ \\
\hline None & 53.92 & 58.59 & -1.053 & .2914 \\
Minor & 19.23 & 18.75 & .136 & .8918 \\
Serious & 11.61 & 12.50 & -.31 & .7566 \\
Fatal & 15.24 & 10.16 & 1.59 & .1118 \\
\hline
\end{tabular}

Damage to the helicopter and injuries for male and female pilots were examined across FAR Part 61 experience levels starting at Category I. There were no significant differences in male and female pilots in Experience Category (CAT) I (99 or fewer hours) regarding damage to the aircraft in categories with sufficient numbers for analysis (Substantial), or injuries where there were enough subjects for analysis (None, Minor). 
Table 4 presents flight hour categories by damage or injury for male and female pilots for those categories where the number of subjects permitted proportional comparisons. As can be seen, there were no significant differences between the genders for any level of flight experiences, as determined by number of flying hours, in either damage or Injury.

Table 4

Damage and Injury by Flight Hours Category for Male and Female Pilots

\begin{tabular}{llcccc}
\hline CAT & $\begin{array}{l}\text { Damage (D) } \\
\text { Injury (I) }\end{array}$ & $\begin{array}{c}\text { Proportion } \\
\text { of males }\end{array}$ & $\begin{array}{c}\text { Proportion of } \\
\text { females }\end{array}$ & Z-score & $p$ \\
\hline CAT I & D-Substantial & 82.14 & 94.44 & -.6348 & .177 \\
& I-None & 63.74 & 66.67 & -.253 & .800 \\
CAT II & D-Substantial & 84.65 & 76.19 & .956 & .339 \\
& D-Destroyed & 14.00 & 23.81 & -1.101 & .271 \\
& I-None & 6.07 & 6.18 & -.111 & .912 \\
& I-Fatal & 12.84 & 19.05 & -.827 & .408 \\
CAT III & D-Substantial & 81.64 & 85.37 & -.61 & .542 \\
& D-Destroyed & 16.49 & 14.63 & .317 & .751 \\
& I-None & 56.82 & 53.66 & .404 & .680 \\
& I-Minor & 20.98 & 21.95 & -.151 & .880 \\
& I-Serious & 9.32 & 14.63 & -1.15 & .250 \\
& I-Fatal & 12.88 & 9.76 & .591 & .555 \\
CAT IV & D-Substantial & 74.53 & 69.57 & .521 & .602 \\
& D-Destroyed & 22.32 & 26.09 & -.431 & .667 \\
& I-None & 53.27 & 56.52 & -.310 & .757 \\
& I-Minor & 18.59 & 21.74 & -.385 & .701 \\
& I-Serious & 11.98 & 13.04 & -.156 & .876 \\
CAT V & D-Substantial & 73.14 & 84.00 & -1.223 & .221 \\
& I-None & 49.74 & 66.00 & -1.221 & .307 \\
& I-Minor & 18.75 & 20.00 & -.159 & .874 \\
\hline
\end{tabular}

An additional analysis compared male and female pilots on accidents and injuries by phase-of-flight. No significant differences were found for any phase of flight (takeoff, maneuvering, etc.) except for hovering. There was a significant difference between male pilots $(10.48 \%)$ and female pilots $(20.55 \%), z=-2.774$, $p=.0055$. Overall, male pilots experienced the most accidents/injuries, in order of the top three, during Landing, Maneuvering, and Climb. Female pilots experienced the most accidents/injuries, in order of top three, during Landing, Hovering, and Maneuvering. 


\section{Discussion}

Using the NTSB eADMS database, differences in helicopter accidents were examined. Previous research with fixed-wing aircraft has not supported, generally, any real differences between male and female pilots particularly in accident rates by gender of the pilot (Bazargan \& Guzhva, 2011; Caldwell \& LeDuc, 1998; Mitchell et al., 2005; Puckett \& Hynes, 2011; Vail \& Ekman, 1986). This study supported the same findings for helicopter pilots of no difference between male and female pilots regarding accidents and injuries. Indeed, female pilots were comparable to male pilots in many ways consistent with fixed-wing findings from Walton and Politano (2016).

When comparing fixed wing pilot error accidents by the phase of flight, Vail and Ekman (1986) found that females had lower accident rates (and lower fatality rates) than males in all phases of flight except for taxiing. The data from this study found hovering as the second highest damage or injury phase for females. Taxiing in helicopters is primarily a hover function unless ground conditions and airframe design (wheels) allow a ground taxi. Female pilots were found to be no different from male pilots in other categories, but performed significantly lower than males in hovering. This tends to support the idea that females may have more difficulty with control touch at a hover and are more likely to have accidents in this mode of flight due to loss of aircraft control as was similarly identified in GA accidents by Baker, Lamb, Grabowski, Rebok, and Li (2001), and Walton and Politano (2016).

\section{Conclusions and Limitations}

This study was an extension of work published by Walton and Politano (2016) that examined fixed-wing GA accident rates of male and female pilots and found that female GA pilots have accidents with higher aircraft damage and personnel injury rates at lower levels of training and experience compared to male pilots, yet significantly fewer accidents compared to male fixed-wing GA pilots at higher levels of experience. For helicopter pilots, no differences were found in accidents and injuries. Helicopter pilots as a whole indicate minimal gender differences.

The data does not address survivability factors by gender or by helicopter size. For example, a two-seat Robinson R-22 cockpit has much less survivable space than does that of a Bell 412. When one considers that most pilots under 1000 hours are traditionally going to fly in a smaller (training) airframe, occupied space 
analysis could provide differences in injury or death between genders. This analysis may further provide evidence of gender differences with helicopter accidents.

One limitation of this study is that it is based on archival data that could have errors in input over the course of the collection period. The USJHSAT found specifically that NTSB helicopter accident investigations lacked the quality and depth that airplane accident investigations received. The JHSAT addressed this issue by creating a helicopter accident checklist to accompany the NTSB investigation protocols (USJHSAT, 2011).

Additionally, the large disparity between the number of male and female pilots placed some constraints on analysis techniques and prevented statistical analysis of some damage and injury categories. An additional difficulty is that frequently commercial operators may operate flights under Part 91 General Operating Flight Rules at the time of the accident as opposed to what the flight operation may be certificated under (Part 133 External Load Operations, Part 135 Commuter and On Demand Operations, Part 137 Agricultural Aircraft Operations etc.).

Several other factors that may bear relevance to future study align towards hereditary/evolutionary, and biological perspectives and these were deeply researched between the 1950's through 1970's. Intuitive explanations from the past that may have matched existing data but did not filter out social/cultural expectations and, therefore, questions about the viability of those explanations can be and have been, raised.

Future research might focus on the age of pilots and the interaction of age and flying hours as an indicator of experience. In addition, future research should examine causes and phase-of-flight factors that might contribute to accidents. 


\section{References}

Baker, S. P., Lamb, M. W., Grabowski, J. G., Rebok, G., \& Li, G. (2001). Characteristics of general aviation crashes involving mature male and female pilots. Aviation, Space, and Environment Medicine, 72(5), 447452.

Bazargan, M., \& Guzhva, V. S. (2011). Impact of gender, age and experience of pilots on general aviation accidents. Accident Analysis and Prevention, 43, 962-970. doi:10.1016/j.aap.2010.11.023

Bryan, C. G. (2014). An Analysis of Helicopter EMS Accidents using HFACS: 2000-2012. Master's Thesis. 31. Retrieved from https://commons.erau.edu/edt/31

Burgess, S. S. (2016). A systems theory approach for studying safety management systems for operations of small helicopter organizations (Doctoral dissertation).

Caldwell, J. A., \& LeDuc, P. A. (1998). Gender influences on performance and recovery sleep in fatigued aviators. Ergonomics, 41, 1757-1770.

Jones, C. M., Braithwaite, V. A., \& Healy, S. D. (2003). The evolution of sex differences in spatial ability. Behavioral Neuroscience, 117(3), 403411. doi: 10.1037/0735-7044.117.3.403.

Li, G., \& Baker, S. P. (2007). Crash risk in general aviation. Journal of American Medical Association, 297, 1596-1598.

McFadden, K. L. (1996). Comparing pilot-error accident rates of male and female airline pilots. International Journal of Management Science, 24(4), 443450.

Mitchell, J., Kristovics, A., Vermeulen, L., Wilson, J., \& Martinussen, M. (2005). How pink is the sky? A cross-national study of the gendered occupation of pilot (Unpublished manuscript). University of Western Sydney, Australia.

Mitchell, J., Kristovics, A. \& Bishop, R. 2010. Glass cockpits in general aviation: A comparison of men and women pilots' perceptions. International Journal of Applied Aviation Studies. 10(2), pp. 11- 29. 
NASA Center for Aerospace Information, \& United States. National Aeronautics and Space Administration. (2006). The implications of handling qualities in civil helicopter accidents involving hover and low speed flight. Hanover, MD: NASA Center for Aerospace Information.

National Transportation Safety Board (NTSB). (1998). Aviation coding manual.

Nix, S., Buckner, S., \& Cercone, R. (2014). A review of risk analysis and helicopter air ambulance accidents. Air Medical Journal, 33(5), 218. doi:10.1016/j.amj.2014.06.011

Puckett, M., \& Hynes, G. E. (2011, March). Feminine leadership in commercial aviation: Success stories of women pilots and captains. Paper presented at the Academic and Business Research Institute International Conference. Nashville, TN.

Shao, B. S., Guindani, M., \& Boyd, D. D. (2014). Causes of fatal accidents for instrument-certified and non-certified private pilots. Accident Analysis and Prevention, 72, 370-375. doi:10.1016/j.aap.2014.07.013

Vail, G. J., \& Ekman, L. G. (1986). Pilot error accidents: Male vs female. Applied Ergonomics, 17(4), 297-303. doi:10.1016/0003-6870(86)90133-X

Szymczak, J. (2008). Human factors and how they contribute to helicopter accidents. Journal of Konbin, 4(1), 233-246. doi:10.2478/v10040-0080020-z

United States. Flight Standards Service, \& United States. Department of Transportation (2012). Helicopter flying handbook. Washington D.C.: U.S. Department of Transportation, Federal Aviation Administration (FAA), Flight Standards Service.

U.S. Joint Helicopter Safety Analysis Team (USJHSAT) (2011). The compendium report: The U.S. JHSAT baseline of helicopter accident analysis (Volume I). Retrieved from http://www.ihst.org/portals/54/US_JSHAT_Compendium_Report1.pdf. 
U.S. Joint Helicopter Implementation Measurement Data Analysis Team (USJHIMDAT) (2014). Comparative report: U.S. data to U.S. JHSAT data (Volume I). Retrieved from http://www.ihst.org/ portals/54/2011\%20Comparative\%20Accident \%20Report\%20Vol\%201.pdf.

Walton, R. O. \& Politano, P. M. (2016). Characteristics of general aviation accidents involving male and female pilots. Aviation Psychology and Applied Human Factors, 6(1), 39-44. 